\title{
Radiofrequency Ablation Study
}

\author{
Aruldass K Angeline ${ }^{1}$, Mahesh Shiva ${ }^{2}$
}

\begin{abstract}
Radiofrequency ablation (RFA) study is a powerful test to diagnose arrhythmias accurately and help treating them effectively. Unlike many diseases of the heart, arrhythmias are normally hidden or be dormant. They come out and strike only when conditions are favorable for them. Electrophysiology (EP) and RFA study uses advanced computed technology to bring the arrhythmia out of its dormancy and shows how to get rid of it. Radiofrequency ablation is often used in conjunction with implantable cardioverter-defibrillator (ICD) therapy in the presence of recurrent ventricular tachycardia (VT) episodes to reduce the frequency of required ICD therapies. It is something like charming a dangerous snake out of its hole and getting rid of it so that there is no chance of it doing harm at all.
\end{abstract}

Keywords: Assess attitude education intervention, Knowledge, Pain.

Pondicherry Journal of Nursing (2019): 10.5005/jp-journals-10084-12134

\section{INTRODUCTION}

Electrophysiology (EP) in the cardiac field is one of the fastest progressing fields in medicine. Cardiac electrophysiology is the study of the heart's electrical system, aimed at analyzing, diagnosing, and treating its electrical activities. Normally, the heart pumps 4,300 gallons of blood everyday through the body's intricate vascular network, and although displacement of blood is its principal function, the heart instigates and finely regulates electrical impulses to create the beats., ${ }^{1,2}$

\section{Case Description}

A 52-year-old male, Mr.X, with euglycemic and hypertension presented to our hospital with the complaints of recurrent episodes of palpitations for past 8 months duration. He is a known case of AV-nodal reentrant tachycardia (AVNRT) on regular medications. At present, admitted for the radiofrequency ablation procedure (RFA) on 24/01/2020.

\section{EXAMINATION}

On admission, patient is afebrile, no pallor, no icterus, and no pedal edema. A pulse rate of 70 beats per minute and blood pressure, 130/70 mm Hg were noted. CVS - S1, S2 heard, and no murmurs. Respiratory system - normal vesicular breath sound heard. No added sounds (Fig. 1).

\section{InVESTIGATIONS}

\section{ECG (Baseline)}

Normal sinus rhythm with 70 beats per minute, normal axis, normal one complete heartbeat in the ECG (PQRST) normal, no significant ST-T changes.

\section{ECG (During Tachycardia)}

Suggestive for AVNRT.

\section{Echo}

Concentric left ventricular hypertrophy, ejection fraction - $66 \%$.

\section{Impression}

The clinical impression was made by the team of cardiologist and radiologist. Features are suggestive for AVNRT (AV-nodal reentrant tachycardia).
${ }^{1}$ Department of Medical Surgical Nursing, Kasturba Gandhi Nursing College, Sri Balaji Vidyapeeth, Puducherry, India

${ }^{2}$ Department of Medical Surgical Nursing, Mahatma Gandhi Medical College and Research Institute, Puducherry, India

Corresponding Author: Mahesh Shiva, Department of Medical Surgical Nursing, Mahatma Gandhi Medical College and Research Institute, Puducherry, India, Phone: +91 9655363663, e-mail: maheshmgmcri@ gmail.com

How to cite this article: Angeline AK, Shiva M. Radiofrequency Ablation Study. Pon J Nurs 2019;12(4):102-104.

Source of support: Nil

Conflict of interest: None

\section{Treatment}

After the diagnosis, patient plans for electrophysiology and radiofrequency ablation on 28/01/2020.

\section{Procedure}

Initial approach is from right femoral vein $7 f$ - St Jude therapy ablation - catheter and 6F - quadripolar catheter - HIS bundle. Right internal jugular vein: $6 \mathrm{~F}$ - Decapolar catheter into coronary

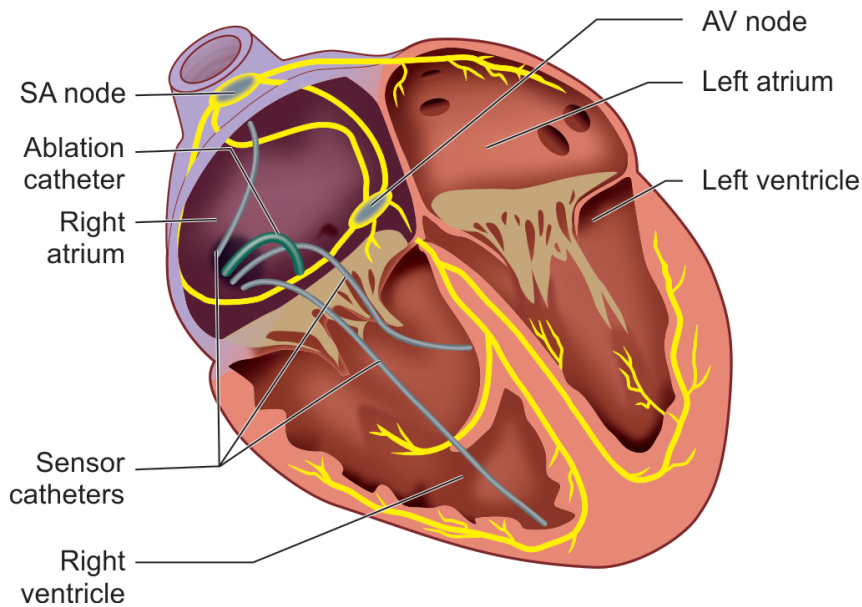

Fig. 1: Conducting system of heart

o The Author(s). 2019 Open Access This article is distributed under the terms of the Creative Commons Attribution 4.0 International License (https://creativecommons. org/licenses/by-nc/4.0/), which permits unrestricted use, distribution, and non-commercial reproduction in any medium, provided you give appropriate credit to the original author(s) and the source, provide a link to the Creative Commons license, and indicate if changes were made. The Creative Commons Public Domain Dedication waiver (http://creativecommons.org/publicdomain/zero/1.0/) applies to the data made available in this article, unless otherwise stated. 
sinus. ${ }^{3}$ Patient is sinus rhythm at baseline at 115 beats/minute. Baseline intervals and intracardiac electrogram were in normal limits. On incremental V pacing, VA conduction was concentric and decremental. ${ }^{4}$ On decremental pacing from PCS, there was evidence of increasing latency from stimulus to atrial. On atrial extrasystoles, evidence of antegrade dual AV nodal physiology and tachycardia was easily inducible. ${ }^{5}$ Tachycardia had features of typical slow-fast AVNRT with onset with AH jump, lined-up VA, and terminating with $A$ on ventricular pacing. Mapping was done with $7 F$ medium curve St Jude therapy ablation catheter. RF energy delivered at 60 degree/40 W/60 seconds with junctional rhythm with good VA conduction. Post RFA, there was dual AV nodal physiology. ${ }^{6,7}$ Short run of atrial tachycardia of four beats induced on aggressive atrial stimulation with spontaneous termination. ${ }^{8,9}$ Successfully slow pathway modification done with RF ablation.

As a part of nursing, management continuously monitored for tachycardia, fever, and hypotension. This is more common and expected. If a fever is above $99^{\circ}$, it is taken as seriously, and the patient may get for blood cultures, $\mathrm{CT}$, drainage, thoracentesis, or antibiotics may be indicated. However, the patient did not have any symptoms. ${ }^{10-14}$ Physicians planned to discharge on next day itself.

After the RFA procedure, patient shifted to a recovery room and quietly observed for four to six hours to prevent bleeding at the catheter site. Patient's heart rate and blood pressure were monitored continuously by the staff nurses to check for complications. After one-day observation, patient was discharged on 30/01/2020 with the follow-up medication advice of Tab clopilet $75 \mathrm{mg}$, Tab. Aztor (atorvastatin) $10 \mathrm{mg}$, and Tab pantodac $40 \mathrm{mg}$ (pantoprazole).

\section{FolLow-UP}

Patient has been followed up regularly, and prognosis was good. Patient was advised for follow-up for first 3 months and then with the interval of 3-6 months intervals.

\section{Discussion}

An electrophysiology study is a test to measure the electrical activities of the heart and to diagnose abnormal rhythms. The EP study and catheter ablation procedure are considered as safe for the patient. The surgeon gets informed consent from the patient with the adequate information about the complication and the follow-up. The EP study is performed safely on both children and adults, with the age group from 3-month-old to 97-year-old. An EP procedure may take up to 3-6 hours, depending on the patient condition. Patient may feel discomfort during the procedures for that patient may get sedatives, depending on the patient condition and the type of procedure.

\section{Will the Electrophysiology Study and Catheter Ablation be Performed at the Same Time?}

Yes, once we identify the exact location of the abnormal rhythm during the electrophysiology study, we apply radiofrequency energy to the particular area during the radiofrequency catheter ablation. It is a combined procedure of both electrophysiology and radiofrequency ablation. ${ }^{15-19}$

\section{How Long Patient will be Hospitalized?}

Patient may return to their home on the same day after the procedure has been done or spend 24 hours in the hospital for observation and return home on the next morning itself. ${ }^{20}$

\section{When can the Patient Start their Normal Day-to-day Activities?}

Patient can resume their normal day-to-day daily activities as soon as they leave the hospital, unless they have any restrictions given by the doctor. Do not lift objects for a few days, until the catheterinsertion site heals.

\section{Conclusion}

This case has been presented for its rarity. Electrophysiology ablation of cardiac is now a safe treatment for many patients. In many countries, it is increasingly considered as firstline therapy as it is potentially curative nowadays.

\section{References}

1. Committee on Clinical Intracardiac Electrophysiologic and Catheter Ablation Procedures Guidelines for Clinical Intracardiac Electrophysiological and Catheter Ablation Procedures. A report of the American College of Cardiology/American Heart Association Task Force on practice guidelines. Developed in collaboration with the North American Society of Pacing and Electrophysiology. Circulation. 1995. vol. 92. p. 673.

2. Morady R. Radio-frequency ablation as treatment for cardiac arrhythmias. N Engl J Med 1999;340(7):534-544.

3. Durrer D, Schoo L, Schuilenburg RM, Wellens HJ. The role of premature beats in the initiation and termination of supraventricular tachycardia in the WPW syndrome. Circulation 1967;36(5):644-662.

4. Coumel P, Cabrol C, Fabiatio A. Tachycardiamente par rythme reciproque. Arch Mal Coeur 1967;60:1830.

5. Harrison L, Gallagher JJ, Kasell J, Anderson RH, Mikat E, Hackel DB, et al. Cryosurgical ablation of the atrioventricular node-His bundle: a new method for producing atrioventricular block. Circulation 1977;55(3):463-470.

6. Cobb FR, Blumenschein SD, Sealy WC, Boineau JP, Wagner GS, Wallace AG. Successful surgical interruption of the bundle of Kent in a patient with Wolff-Parkinson-White syndrome. Circulation 1968;38(6): 1018-1029.

7. Wellens HJJ, Electrical Stimulation of the Heart in the Study and Treatment of Tachycardias, 1971 LeidenStenfert Kroese.

8. Coumel P, Aigueperse J, Perrault MA, Fantoni A, Slama R, Bouvrain Y. Detection and attempted surgical exeresis of a left auricular ectopic focus with refractory tachycardia. Favorable outcome. Ann Cardiol Angeiol (Paris) 1973;22(3):189-199.

9. Sundt TM, Camillo CJ, Cox JL. The maze procedure for cure of atrial fibrillation. Cardiol Clin 1997;15(4):739-748.

10. Gonzalez R, Scheinman MM, Margaretten W, Rubinstein M. Closedchest electrode-catheter technique for $\mathrm{His}$ bundle ablation in dogs. Am J Physiol 1981;241(2):H283-H287.

11. Scheinman MM, Morady F, Hess DS, Gonzalez R. Catheter-induced ablation of the atrioventricular junction to control refractory supraventricular arrhythmias. JAMA 1982;248(7):851-855.

12. Gallagher JJ, Svenson RH, Kasell JH, German LD, Bardy GH, Broughton $\mathrm{A}$, et al. Catheter technique for closed-chest ablation of the atrioventricular conduction system. N Engl J Med 1982;306(4): 194-200.

13. Weber H, Schmitz L. Catheter technique for closed-chest ablation of an accessory atrioventricular pathway. N Engl J Med 1983;308(11): 653-654.

14. Morady F, Scheinman MM. Transvenous catheter ablation of a posteroseptal accessory pathway in a patient with the Wolff-Parkinson-White syndrome. N Engl J Med 1984;310(11): 705-707.

15. Hartzler GO. Electrode catheter ablation of refractory focal ventricular tachycardia. J Am Coll Cardiol 1983;2(6):1107-1113. 
16. Jackman WM, Wang X, Friday KJ, Roman CA, Moulton KP, Beckman KJ, et al. Catheter ablation of accessory atrioventricular pathways by radiofrequency current. N Engl J Med 1991;324(23): 1605-1611.

17. Calkins H, Sousa J, El-Atassi R, Rosenheck S, de Buitleir M, Kou WH, et al. Diagnosis and cure of the Wolff-Parkinson-White syndrome of paroxysmal supraventricular tachycardia during a single electrophysiologic test. N Engl J Med 1991;324(23):1612-1618.

18. Huang SK, Bharati S, Graham AR, Lev M, Marcus Fl, Odell RC, et al. Closed chest catheter dessication of the atrioventricular junction using radiofrequency energy - a new method of catheter ablation. J Am Coll Cardiol 1987;9(2):349-358.

19. Kay GN, Epstein AE, Dailey SM, Plumb VJ. Role of radiofrequency ablation in the management of supraventricular arrhythmias: experience in 760 consecutive patients. J Cardiovasc Electrophysiol 1993;4(4):371-389.

20. Haissaguerre M, Warin JF, Lemetayer P, Saoudi N, Guillem JP, Blanchot P. Closed-chest ablation of retrograde conduction in patients with atrioventricular nodal reentrant tachycardia. N Engl J Med 1989;320(7):426-433. 